\title{
The ecological importance of unregulated tributaries to macroinvertebrate diversity and community composition in a regulated river
}

\author{
Victoria S. Milner · Sarah M. Yarnell • Ryan A. Peek
}

Received: 17 November 2017/Revised: 15 November 2018/ Accepted: 20 November 2018/Published online: 1 December 2018 (C) The Author(s) 2018

\begin{abstract}
In regulated rivers, dams alter longitudinal gradients in flow regimes, geomorphology, water quality and temperature with associated impacts on aquatic biota. Unregulated tributaries can increase biodiversity in regulated environments by contributing colonists to the main channel and creating transitional habitats at a stream junction. We assessed whether unregulated tributaries influence macroinvertebrate communities in two mainstem rivers during summer low-flows. Three tributary junctions of upland cobblegravel bed streams were surveyed in an unregulated and a regulated river in the Sierra Nevada Mountains, California, USA. We found distinct physical habitat conditions and increased macroinvertebrate abundance and diversity in unregulated tributaries on the regulated river, but macroinvertebrate diversity did not increase downstream of tributary junctions as predicted. On the unregulated river, macroinvertebrate diversity was similar in upstream, downstream and unregulated tributary sites. Our findings highlight that
\end{abstract}

Handling editor: Marcelo S. Moretti

V. S. Milner $(\bowtie)$

River Science Research Group, School of Science and the Environment, University of Worcester, Henwick Grove, Worcester WR2 6AJ, UK

e-mail: v.milner@worc.ac.uk

S. M. Yarnell · R. A. Peek

Center for Watershed Sciences, University of California, Davis, CA, USA unregulated tributaries support high macroinvertebrate diversity and heterogeneous communities compared to the mainstem sites in a regulated river, and thus likely support ecological processes, such as spillover predation, breeding and refugia use for mobile taxa. We suggest unregulated tributaries are an integral component of river networks, serving as valuable links in the landscape for enhancing biodiversity, and should be protected in conservation and management plans.

Keywords Tributary junction - Benthic macroinvertebrates · Hydropower - Regulation · Physical habitat

\section{Introduction}

Hydropower dams and other river impoundments have fragmented river ecosystems with associated declines in habitat heterogeneity, biodiversity (Vörösmarty et al., 2010; Reidy Liermann et al., 2012) and ecological and hydrological connectivity (Pringle, 2003). The successive flow pulses from regulated hydro-peaking operations alter the natural flow regime through decreasing peak flow magnitude and increasing annual baseflows and rates of flow change (Junk et al., 1989; McLaughlin et al., 2014). Frequent and rapid flow fluctuations impact physical conditions, including channel geometry (i.e. slope, channel 
width), sediment composition and trigger shifts in physicochemical parameters (Bunn \& Arthington, 2002; Smith et al., 2017). Flow modifications can also indirectly cause loss or declines in suitable habitats for aquatic biota (Vehanen, 2000). The combined effects of altered flow and other abiotic factors triggered by dams alter ecological processes and shape the structure and functioning of downstream communities (Bunn \& Arthington, 2002; Ellis \& Jones, 2013).

Many studies have investigated the effect of flow regulation on benthic macroinvertebrates (e.g. Jones, 2011, 2013; Patterson \& Smokorowski, 2011; see Ellis \& Jones, 2013 for review). Macroinvertebrate abundance or biomass can increase or decrease nearest a dam's discharge depending on flow variability and resource subsidies, but taxonomic diversity is characteristically low (Cushman, 1985; Camargo \& Voelz, 1998; Bruno et al., 2010; Ellis \& Jones, 2013). Changes in functional feeding groups (FFGs) and taxonomic orders typically occur for many kilometres downstream (Céréghino et al., 2002). Filter-feeders, such as Simuliidae (Diptera) and collector-gatherers, including Orthocladiinae (Chironomidae; Diptera) are often abundant near dams with constant baseflow conditions due to increases in fine particulate food supplies from upstream reservoirs (Petts, 1988; Munn \& Brusven, 2004; Jones, 2011). However, other filterfeeders including Hydropsychidae (Trichoptera) are intolerant of rapid rates of flow changes (Troelsup \& Hergenrader, 1990; Boon, 1993), and appear to favour stable flows for feeding nets to function (Hauer et al., 1989; Boon, 1993). Therefore, filter-feeder abundances near dams vary depending on the advantages of a plentiful food source (seston) from the upstream reservoir versus the energy expenditure of repairing net damage due to variable flows (Boon, 1993). While FFG patterns are valuable in identifying benthic community modifications downstream of dams, distinct longitudinal trends in taxonomic order often occur in regulated rivers. Ephemeroptera abundances vary below dams depending on a specific taxa's habitat requirements, while Plecoptera density and diversity are normally low below dams with variable recovery downstream (Jones, 2011; Ellis \& Jones, 2013). Plecoptera density appears to decrease due to temperature, sediment and food resources modified by the hydro-peaking operations of a dam. In contrast, Dipterans and oligochaetes frequently occur in large abundances immediately downstream of dams (Ward,
1975). Simuliids often use silk pads to hook onto the bed substrate in order to avoid high shear stress associated with flow pulses (Moss, 2010). Many oligochaetes (e.g. Naididae) may burrow into the hyporheic zone to avoid high hydraulic stress (Jones, 2011). While previous work (e.g. Céreghino \& Lavandier, 1998; Céréghino et al., 2002; Patterson \& Smokorowski, 2011; Kjærstad et al., 2018) has examined changes in macroinvertebrate community structure below dams, fewer studies have explored the potential ameliorating effects of unregulated tributaries on benthic invertebrate communities in regulated rivers.

Unregulated tributaries can modify physical and ecological conditions in a main channel via influxes of water, coarse sediment, nutrients and organic matter (Bruns et al., 1984). The hydrological and sediment inputs can trigger changes in channel geometry, substrate characteristics, hydraulics, water quality and alter physical habitat availability (Rice \& Greenwood, 2001). These geomorphic transitions at tributary junctions induce physical habitat heterogeneity to environments affected by flow regulation and may reduce the biotic effects of impoundments on the main channel through changes in ecological processes and patterns (Ward \& Stanford, 1995; Johnson, 2002).

Tributaries allow bi-directional filtering (i.e. movement of aquatic biota from mainstem to tributary habitats) that influences organism dispersal and population persistence (Thornburgh \& Gido, 2010; Wilson \& McTammany, 2014; Czeglédi et al., 2016), which strongly affects metacommunity dynamics and biodiversity patterns (Tonkin et al., 2018). Key aquatic dispersal mechanisms include invertebrate drift from tributary to downstream mainstem populations (i.e. direct mass effects; Wilson \& McTammany, 2014), larval upstream dispersal over short distances (Elliott, 2003) and upstream directional dispersal as adults (Hershey et al., 1993). Therefore, tributaries provide opportunities for mobile taxa, and support ecological processes, such as spill-over predation (Power \& Dietrich, 2002), breeding and refugia use. Tributaries can also increase primary productivity by adding nutrients, organic matter and inorganic sediment to recipient channels, which is likely to modify food availability and habitats, thus leading to a higher diversity of macroinvertebrates (Knispel \& Castella, 2003; Wallis et al., 2009), and creating biodiversity 'hotspots' in river systems (Power \& Dietrich, 2002; 
Benda et al., 2004; Clarke et al., 2008). However, not all previous work has found a tributary effect in regulated and unregulated river systems. Stevens et al. (1997) explored tributary influences on benthic invertebrate communities in regulated Colorado rivers, and found that dam-related impacts on water clarity, flow and water temperature overrode geomorphological drivers (i.e. tributary effects) on habitat availability and benthic invertebrate communities. In contrast, Vinson (2001) found macroinvertebrate taxon richness in the regulated Green River below Flaming Gorge dam in Utah increased downstream of an unregulated tributary. Similarly, Katano et al. (2009) found that a tributary in the Agi-gawa River, in central Japan increased taxon richness and diversity, but decreased benthic invertebrate density downstream of a tributary junction. Thus, the role of unregulated tributaries in attenuating the effects of river regulation on benthic macroinvertebrate communities remains uncertain.

Our study examines the potential role of unregulated tributaries in influencing benthic macroinvertebrate community diversity in two Mediterraneanmontane rivers, one unregulated and one regulated by a hydro-peaking dam. Our first two hypotheses were (1) unregulated tributaries will change physical habitat downstream of junctions in the regulated and unregulated river, and (2) unregulated tributaries will alter macroinvertebrate diversity and community composition downstream of junctions in both rivers. In addition, we tested a third hypothesis that FFG patterns will vary longitudinally in the regulated river such that predators would decrease with increasing distance downstream from the dam, while collectorgatherers and filterers would increase. We expected physical habitat to change downstream of a junction due to additions of water, coarse sediment, nutrients and organic matter from a tributary, and that invertebrate communities would respond to this habitat transition. Whilst many filter-feeders and collectorgatherers are often enhanced below dams to an increase in fine particulate food supplies (Patterson \& Smokorowski, 2011; Ellis \& Jones, 2013), we hypothesise that the rapid rates of flow changes will override this potential food benefit and cause low abundance of filter-feeders and collector-gatherers with communities recovering further downstream.

The results of this observational study will contribute to understanding the magnitude of ecological impacts due to flow regulation and provide a preliminary assessment of the contribution of unregulated tributaries to biotic patterns in regulated and unregulated river environments.

\section{Materials and methods}

Study area and sites

The unregulated North Fork American River (NFAR) and the regulated Middle Fork American River (MFAR) in the Sierra Nevada Mountains, California, USA were chosen for this study (Fig. 1). The unregulated NFAR and regulated MFAR possess a drainage basin $601 \mathrm{~km}^{2}$ and $1572 \mathrm{~km}^{2}$ respectively. Both rivers are tributaries of the American River (drainage basin of $5568 \mathrm{~km}^{2}$ ), which flows south-west into the Sacramento River. The American River drainage basin experiences a spring snowmelt flow regime, typical of a Mediterranean-Montane climate. Most precipitation (>90\%) falls during the winter and spring months (November to April), followed by a spring snowmelt pulse (April to June), and a dry low flow season during summer and early fall (July to October; Anderson et al., 2012). The NFAR possesses a mean annual flow of $26.11 \mathrm{~m}^{3} \mathrm{~s}^{-1}$ (1987-2015), measured at the North Fork American gauging station (United States Geological Survey [USGS], 2017; Fig. 1). The unregulated NFAR exhibits a natural hydrograph such that it responds to increased flow conditions post precipitation and runoff events (USGS, 2017). In contrast, the regulated MFAR has a mean annual flow of $31.86 \mathrm{~m}^{3} \mathrm{~s}^{-1}$ (1987-2015), recorded at the Middle Fork American River gauging station that is positioned downstream of the Oxbow Powerhouse and Ralston Afterbay Dam (Fig. 1). The regulated MFAR experiences decreased flow magnitude and variability during winter, but elevated daily flow changes of greater magnitude and frequency compared to the NFAR in spring and summer due to hydropower operations. In the MFAR, flow fluctuations vary between approximately $2 \mathrm{~m}^{3} \mathrm{~s}^{-1}$ (minimum instream flow requirements) and $34 \mathrm{~m}^{3} \mathrm{~s}^{-1}$ across a $4-8 \mathrm{~h}$ period (Placer County Water Agency, 2007). Hydropeaking varies annually (i.e. from January to July) depending on antecedent weather conditions, but usually occurs from April to September/October, which elevates the magnitude of daily flow discharges 


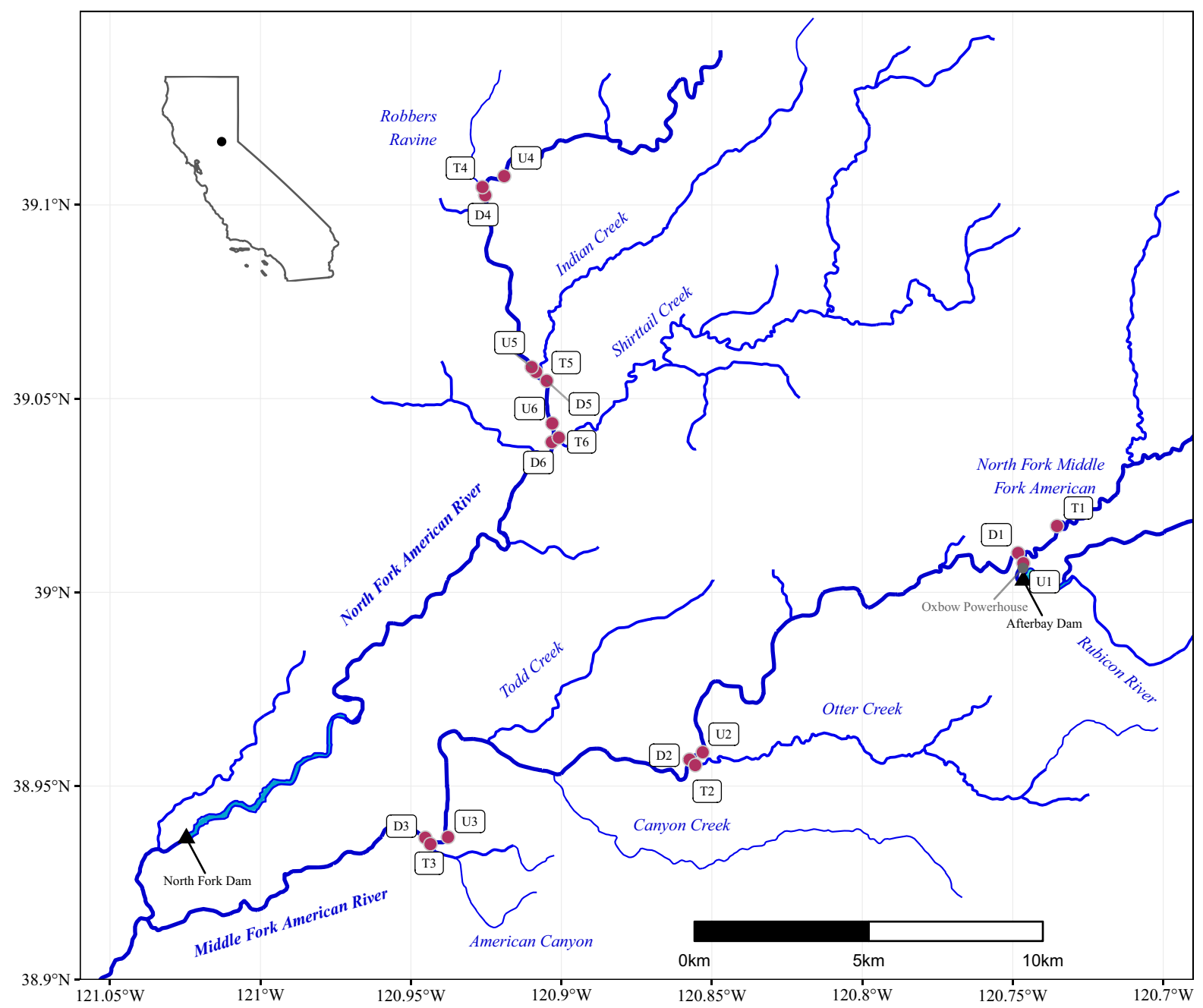

Fig. 1 Map showing the location of the study sites in the NFAR (North Fork American River) and the MFAR (Middle Fork American River). A black filled triangle symbol denotes the positioning of gauging stations on each river

throughout the summer months compared to the NFAR (Fig. 2). In 2012 (the year of the study period), hydro-peaking took place from early May to late September. On the MFAR, hydro-peaking is the main alteration to the flow regime occurring downstream of the dam. The flow regime responds to precipitation and runoff events typically from October to April.

The two drainage basins are upland in character with the study sites positioned between $201 \mathrm{~m}$ to $384 \mathrm{~m}$ in elevation, occurring on moderate to steep slopes, in confined valleys with intermittent bedrock outcrops, coarse substrates and upland channel morphologies comprising cascades, steps, riffles and pools. Both rivers have a meandering planform, characterised by few vegetated islands and predominantly cobble-gravel point, medial and lateral bars. Land use in both drainage basins is dominated by a mature mixed oak forest with chaparral present on drier slopes $(99 \%$ and $<90 \%$ for the NFAR and MFAR respectively) with smaller occurrences of urban dwellings in the lower part of the watershed ( $1 \%$ and $\sim 7 \% \%$ for the NFAR and MFAR; California Protected Areas, 2018).

For this study, an approximate $9.3 \mathrm{~km}$ of the NFAR and $30.4 \mathrm{~km}$ section of the MFAR were chosen to assess three tributary junctions each, based on accessibility (Fig. 1). Each tributary junction was split into three zones; with one study site located on the tributary (T) and two sites on the mainstem upstream (U) and downstream (D) of the junction, respectively. The 
Fig. 2 Daily average discharge over the study period for the MFAR (a) and the NFAR (b) at the USGS 11427000 and USGS 11413000 gauging stations during 2012. Insert plots showing the study period for July 2012 and a grey filled triangle indicates the sampling date
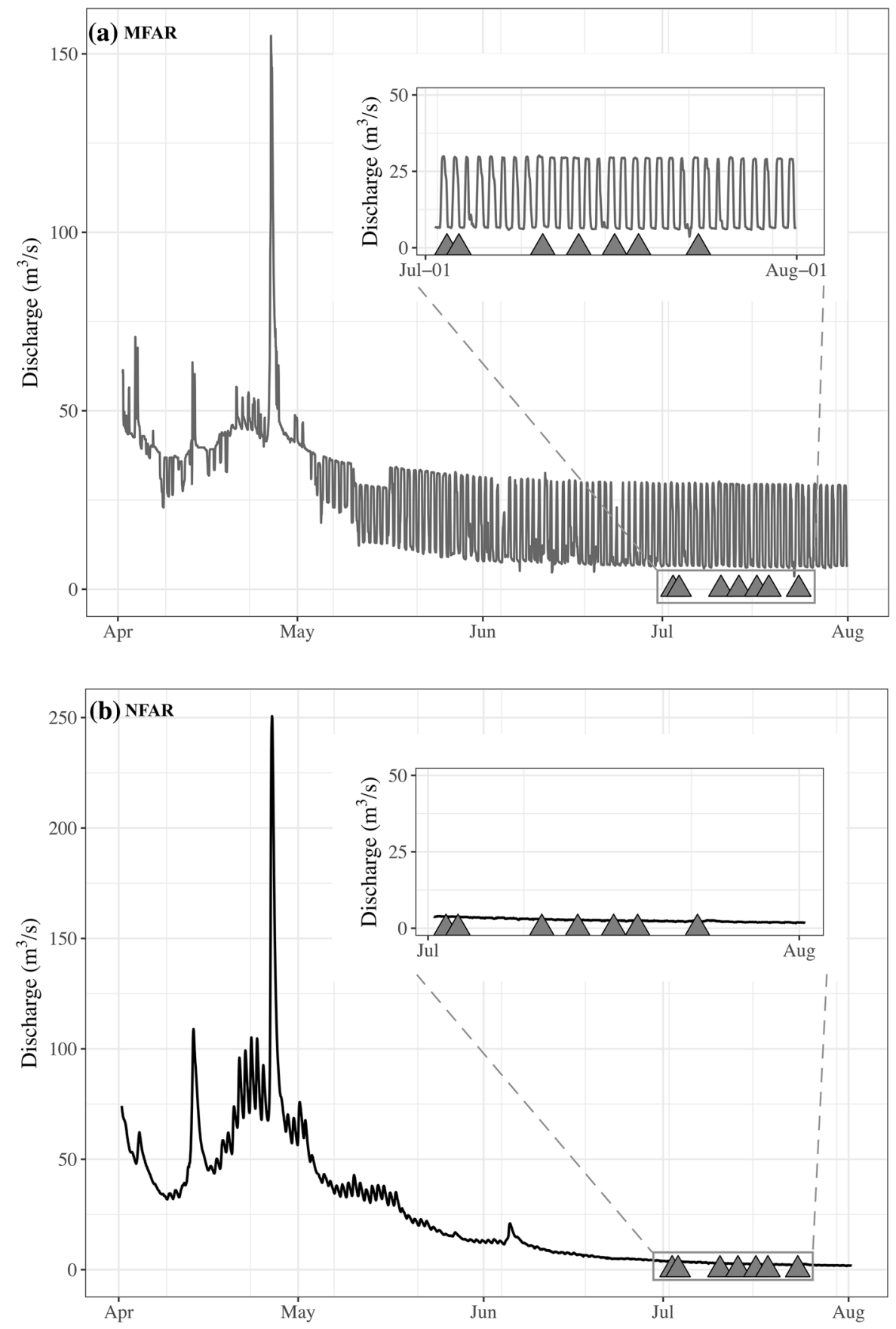

positioning of the study sites was based at set distances in channel-width units, whereby one channel width was defined as the width of the mainstem at the tributary (MacNally et al., 2011). All study sites (i.e. $\mathrm{U}, \mathrm{D}$ and T) were located at 0.5-1 channel widths of the apex of the tributary. On the MFAR, site 1 (i.e. U1) was located $0.1 \mathrm{~km}$ downstream of the Oxbow
Powerhouse and Ralston Afterbay Dam and immediately upstream of the North Fork of the MFAR (referred to as the NFMF tributary; Fig. 1). Site U2 (18.1 km downstream of the dam) was positioned upstream of Otter Creek, and site U3 $(30.3 \mathrm{~km}$ downstream of the dam) was placed above American Canyon Creek. Sites on the NFAR were determined by 
tributary location and accessibility. Approximately $7.1 \mathrm{~km}$ separated Robber's Ravine and Indian Creek tributaries, whereas Indian Creek and Shirttail Creek tributaries were $1.9 \mathrm{~km}$ apart (Fig. 1). Study sites were located in riffles due to the presence of this habitat at all mainstem and tributary sites.

Macroinvertebrate sampling and environmental data collection

Fieldwork was carried out over a three-week period in July 2012. On the regulated MFAR, sampling occurred at the base flow (i.e. $3.5-7.1 \mathrm{~m}^{3} \mathrm{~s}^{-1}$ ) of the flow pulse generated by hydro-peaking operations (Fig. 2). Velocity was measured with an electromagnetic flowmeter (Marsh McBirney Flo-mate 2000, Maryland, USA) at 0.6 depth for $30 \mathrm{~s}$ at regular intervals across a cross-section profile at each site along with water depth. Grain size distribution of the bed sediment was characterised by measuring the width of 100 randomly selected particles using Wolman's method (Leopold et al., 1964).

Water temperature, conductivity (at local temperature), total dissolved solids (TDS), $\mathrm{pH}$ and dissolved oxygen (DO) were recorded at each site using a handheld multi-parameter YSi probe (YSi v.556). Water temperature was measured at 15-min intervals at each tributary and at either an upstream or downstream mainstem site (i.e. the same location as biological sampling) using a temperature logger (Hobo Pro V2 and Solinst Levelogger; see Table 1 for the location of the temperature loggers). Daily mean, minimum and maximum summer water temperatures were determined for a 69-90 day period (depending on site access and logger installation) between the beginning of June and the end of August. Our main interest was to detect temperature differences between mainstem and tributary sites. A stage data logger (Solinst Edge Levelogger Model 3001) was also installed on the mainstem of the MFAR and the NFAR (i.e. at sites D1, D2 and U4) and on the NFMF and Shirttail Creek tributaries.

Three cross-sectional profiles were established per study site (i.e. within a riffle). Benthic macroinvertebrates were collected by kicking substrate within a $0.5 \mathrm{~m} \times 0.5 \mathrm{~m}$ area for one minute, so that dislodged organisms were washed into a $500 \mu \mathrm{m}$ kick net. Sampling points were positioned at four equidistant locations across each of the cross-section profiles. All 12 one-minute kicks were combined into a single riffle sample. We sampled benthic macroinvertebrates only from riffles to decrease small-scale habitat variability. Invertebrates were preserved with $70 \%$ ethanol in the field and passed through a $250 \mu \mathrm{m}$ sieve to separate invertebrates and organic matter in the laboratory (Stubbington et al., 2015). Efforts were made to sample comparable habitat (e.g. similar substrate, depth and flow) to decrease variability in other potentially confounding factors. Ephemeroptera, Plecoptera, Trichoptera, Odonata, Coleoptera, Diptera and Gastropoda were identified to genus, with the exception of Chironomidae and Acari, which were typically identified to family and order respectively. Identification was made using the keys of Wiggins (2000) and Merritt et al. (2008).

\section{Statistical analyses}

Total invertebrate abundance (TIA; i.e. the number of individuals), taxon richness and Shannon-Wiener diversity index were determined for all sites on both rivers using the Diverse function in PRIMER 6 (Clarke \& Gorley, 2006). Prior to the tests, the faunal indices (e.g. TIA, taxon richness and Shannon-Wiener diversity) and the physical habitat data were examined to ensure compliance with the underlying assumptions of parametric statistical tests (e.g. a normal distribution and homogeneity of variances). We used a Shapiro-Wilk W test to examine the data distribution, and a Levene's test for homogeneity of variances (equal variance can be assumed where $P>0.05$ ). Faunal indices and physical habitat data were squareroot transformed where necessary. Variation in faunal indices and physical habitat among grouped upstream, downstream and tributary sites were identified using a one-way analysis of variance (ANOVA) with the use of Tukey post hoc tests to examine where any statistical differences between sites were present. Site (i.e. all upstream, downstream and tributary sites) was included as a fixed factor and tributary junction group (i.e. the upstream, downstream and tributary site at each tributary) was incorporated as a random effect. The analysis was conducted in SPSS (version 24, IBM Corporation, New York).

Differences in macroinvertebrate community composition between upstream, downstream and tributary 


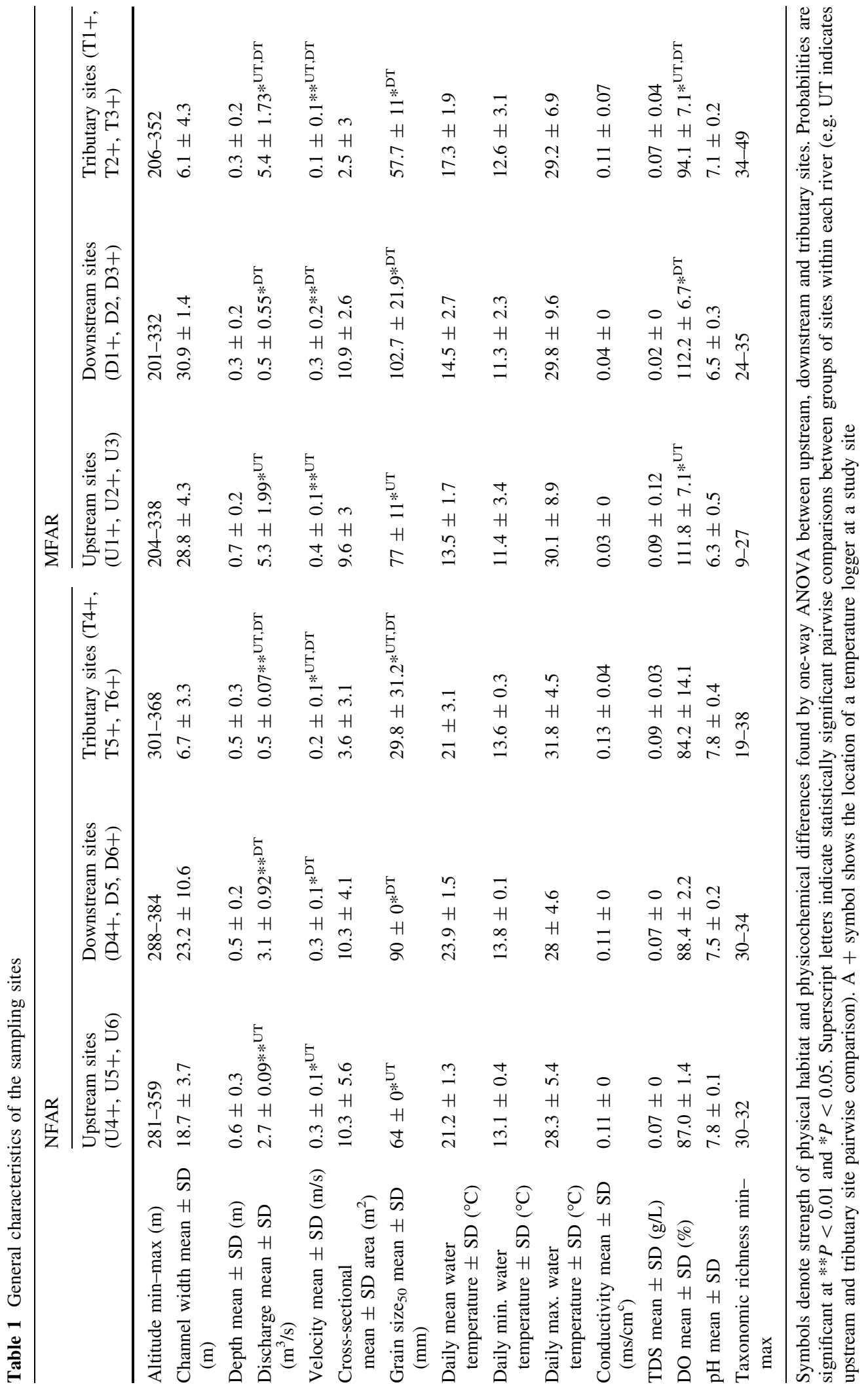


sites on each river were tested using a one-way permutational multivariate analysis of variance (PERMANOVA) and summarised visually using a Principal Co-ordinates Analysis (PCoA) ordination (Anderson et al., 2008). For the PERMANOVA analysis and PCoA ordination, sites were combined to form three groups (upstream, downstream and tributary) within each river, and the community composition between each group was analysed. Before the analyses, a fourth-root transformation was applied on the invertebrate abundance data to reduce the effect of the most abundant taxa. BrayCurtis distance between sites was used to form similarity matrices for the invertebrate data. Monte Carlo $P$-values were employed to identify significant differences between groups because of the low sample sizes (Hladyz et al., 2012). When significant differences were present, post hoc comparisons were undertaken to determine differences in invertebrate community composition between upstream, downstream and tributary sites. PERMANOVA and PCoA were run in PERMANOVA+ for PRIMER (Anderson et al., 2008).

Longitudinal trends in benthic invertebrates with each river (i.e. main channel sites: U1, D1, U2, D2, U3 and D3 for the MFAR and U4, D4, U5, D5, U6 and D6 for the NFAR) were assessed by classifying invertebrates into taxonomic orders and functional feeding groups (FFGs). Taxonomic orders included Coleoptera, Diptera, Ephemeroptera, Plecoptera, Trichoptera and Oligochaeta and FFGs comprised filterers, grazers, collector-gatherers, shredders, scrapers and predators according to Merritt et al. (2008). Data on invertebrate abundance for each taxonomic order and FFG category were scaled from 0 to 1.0 . Scaling the data permits comparisons of rivers with varying productivity (invertebrate abundance) to be contrasted via the use of a common scale (Jones, 2011). Simple linear regression identified the significance, slope and changes in invertebrate orders and FFG with distance downstream. Linear regression was carried out in SPSS v24.

\section{Results}

Physical habitat conditions between sites

Physical habitat conditions varied between rivers, and between upstream, downstream and tributary sites (Table 1). In both drainage basins, one-way ANOVA revealed differences in discharge (NFAR $F=21.36$, $P<0.01 ;$ MFAR $F=9.97, \quad P<0.05)$, velocity (NFAR $F=6.12, \quad P<0.05 ;$ MFAR $F=12.88$, $P<0.01)$ and mean grain size (NFAR $F=8.41$, $P<0.05 ; \quad$ MFAR $F=6.3, \quad P<0.05)$ between upstream, downstream and tributary sites. On both rivers, post hoc analysis indicated upstream and downstream sites possessed higher discharges (NFAR $P<0.01$; MFAR $P<0.05)$ and faster velocities than tributary sites (all $P<0.05$ ), but no significant discharge or velocity differences existed between upstream and downstream sites on the NFAR or the MFAR (both $P>0.05$ ). Mean grain size was coarser in upstream and downstream sites compared to tributaries (all $P<0.05$ ), but not between upstream and downstream sites in both rivers (both $P>0.05$ ). Overall, all tributaries had significantly slower velocities (NFAR $0.08-0.21 \mathrm{~m} \mathrm{~s}^{-1}, \quad$ MFAR $0.048-0.2 \mathrm{~m} \mathrm{~s}^{-1}$ ) and finer mean substrates (NFAR 1-64 mm, MFAR 2.8-64 mm) than upstream and downstream sites.

On the regulated MFAR, mean, minimum and maximum daily summer water temperature, TDS and $\mathrm{pH}$ did not differ between sites (all $P>0.05$ ). However, upstream and downstream sites possessed higher DO concentrations (ANOVA $F=5.3$, $P<0.05)$ than tributaries. On the unregulated NFAR, all sites were characterised by low conductivity and TDS values, and slightly alkaline conditions (Table 1). Mean, minimum and maximum daily summer water temperature (all $P>0.05$ ) did not vary significantly between sites.

Macroinvertebrate diversity and community composition between sites

A significant difference in mean TIA among upstream $(\bar{x}=286.3)$, downstream $(\bar{x}=674.7)$ and tributaries $(\bar{x}=878.7)$ was identified on the MFAR (ANOVA $F=6.29, P<0.05$; Fig. 3a). Post hoc tests demonstrated that TIA was significantly greater in tributaries than upstream sites $(P<0.05)$, but no difference in 
Fig. 3 Total invertebrate abundance (TIA, a) and taxonomic richness (b) variations in the regulated MFAR and the unregulated NFAR. Clear bars are tributary sites (T), solid bars are mainstem sites upstream (U) and downstream (D) of the tributary
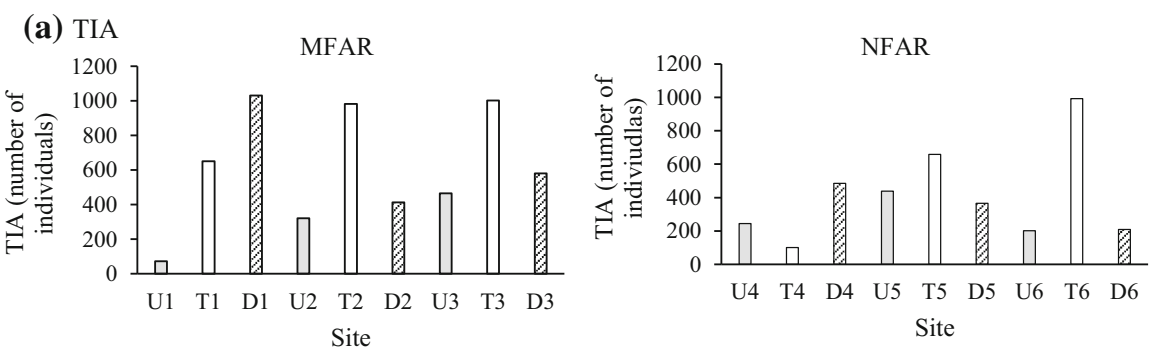

(b) Taxonomic richness

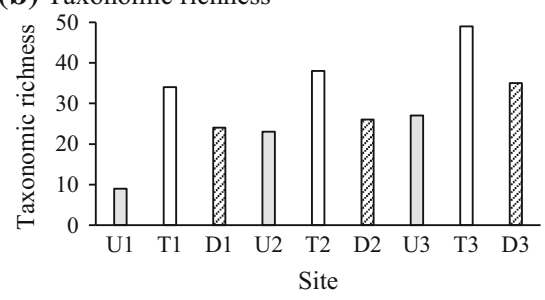

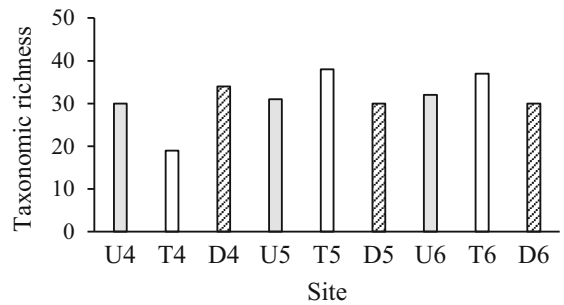

TIA occurred between upstream and downstream sites or tributary and downstream sites (both $P>0.05$ ). MFAR tributaries showed significantly greater mean taxon richness $(\bar{x}=40.3$; ANOVA $F=5.3, P<0.05)$ than upstream $(\bar{x}=19.7)$ or downstream sites $(\bar{x}=28.3)$. However, the effect of tributary junction group (i.e. a random factor) was significant $(P<0.05)$ and explained $87.9 \%$ (Partial Eta Squared value) of the variance in taxon richness, denoting a strong within group correlation (Fig. 3a). The Shannon-Wiener index also varied between upstream, downstream and tributary sites on the MFAR (ANOVA $F=0.42$, $P>0.05)$. Tributary sites $(\bar{x}=0.83)$ possessed a more diverse invertebrate community structure than upstream and downstream sites $(P<0.05)$, while upstream $(\bar{x}=0.69)$ and downstream sites $(\bar{x}=0.74)$ were not statistically different from each other.

On the unregulated NFAR, mean TIA was higher in tributaries $(\bar{x}=583.7)$ and lower in upstream $(\bar{x}=295.3)$ and downstream sites $(\bar{x}=353$; Fig. 3a), whereas mean taxon richness was very similar between all sites $(\bar{x}=31.0,31.3$ and 31.3 taxa for upstream, downstream and tributary sites, respectively; Fig. 3b). ANOVA revealed no significant difference in TIA between upstream, downstream and tributary sites $(F=0.88, P>0.05)$. The ANOVA tests also indicated taxonomic richness $(F=0.003$, $P>0.05)$, and Shannon-Wiener index $(F=0.003$, $P>0.05$ ) did not differ between NFAR sites (mean Shannon-Wiener values $0.86,0.77$ and 0.88 for upstream, tributary and downstream sites, respectively).
One-way PERMANOVA indicated that macroinvertebrate community composition differed significantly between upstream, downstream and tributary sites on the regulated MFAR $(F$-ratio $=1.7$, $P<0.05)$. Pairwise tests showed upstream and downstream sites differed from tributary sites in macroinvertebrate community composition (both $P<0.05$ ), while upstream versus downstream sites possessed similar community composition $(P>0.05)$. On the unregulated NFAR, macroinvertebrate community composition was similar between upstream, downstream and tributary sites $(F$-ratio $=0.95, P>0.05)$. The PERMANOVA analysis is visually supported by a PCoA ordination (Fig. 4). Upstream and downstream sites on the MFAR cluster together in the ordination and separate from the cluster of MFAR tributary sites (Fig. 4a). However, the ordination of site U1 was dissimilar to these two clusters, diverging from all other sites on PCO1. Site UI is located immediately downstream of the Ralston Afterbay Dam and had lower abundances and taxonomic richness. Most NFAR samples grouped together in the PCoA ordination (Fig. 4b), indicating very similar macroinvertebrate assemblages (as demonstrated by PERMANOVA). However, the positioning of site T4 (i.e. Robber's Ravine tributary) on the left side of the PCoA ordination revealed a different macroinvertebrate composition to the other NFAR sites. Robber's Ravine was characterised by low abundance and low taxonomic richness, which may be due to low discharges (i.e. $0.553 \mathrm{~m}^{3} \mathrm{~s}^{-1}$ ) associated with river 
(a)

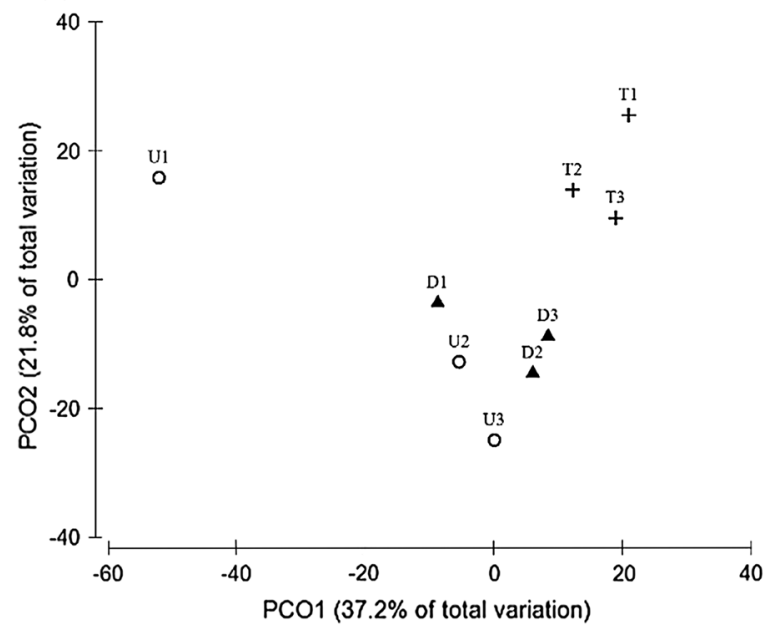

(b)

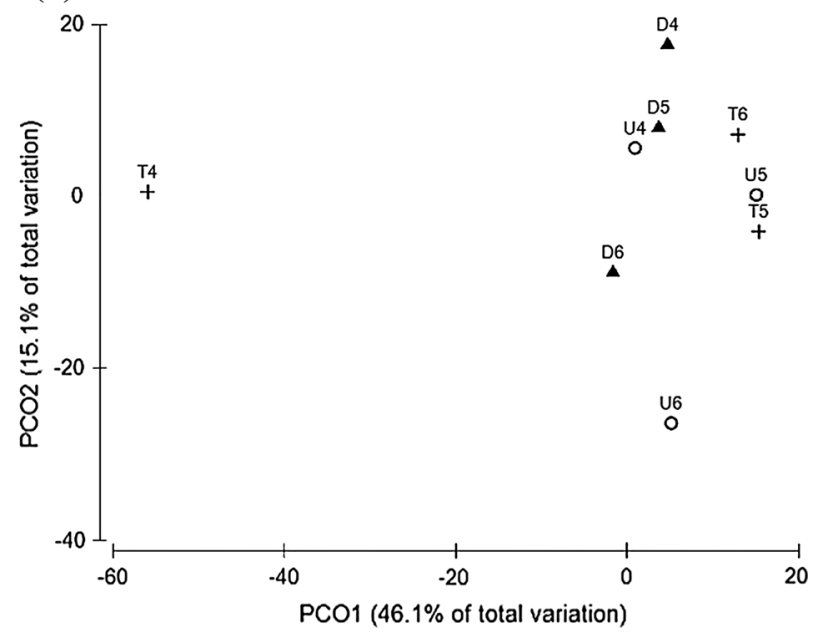

Fig. 4 Principal co-ordinates analysis (PcoA) ordination plots of macroinvertebrate community composition on the MFAR (a), and the NFAR (b)

contraction that created unfavourable habitat conditions (i.e. higher water temperatures).

Longitudinal patterns in benthic invertebrates

In the MFAR, Plecoptera and Ephemeroptera [particularly Baetis sp. (Baetidae), Rhithrogena sp. (Heptageniidae), Ephemerella sp. (Ephemerellidae), Serratella sp. (Ephemerellidae) and Calineuria californica (Banks, 1905) (Perlidae)], both sensitive taxa groups, increased downstream $\left(R^{2}=0.68, P<0.05\right.$, and $R^{2}=0.86, P<0.01$ respectively; Table 2$)$. Other key taxonomic groups, such as Coleoptera, Diptera, Trichoptera and Oligochaeta showed no abundance variations with distance downstream (all $P>0.05$ ). In the unregulated NFAR, no significant longitudinal trends in macroinvertebrates classified by order were present. At mainstem sites on the regulated MFAR, feeding guilds varied longitudinally with increases of filter-feeders and collector-gatherers with distance downstream $\quad\left(R^{2}=0.67, \quad P<0.05 ; \quad R^{2}=0.65\right.$, $P<0.05$, respectively), while no change occurred in grazers, shredders, scrapers or predators (Table 2). The unregulated NFAR demonstrated no significant longitudinal differences in any other proportions of feeding guilds (Table 2).

\section{Discussion}

Influence of tributaries on physical habitat conditions downstream of junctions

This observational study is a detailed snapshot of the ecological importance of tributaries on physical habitat and benthic invertebrate communities in an unregulated and a regulated river in the Sierra Nevada Mountains. Earlier work has found some tributaries can increase physical habitat heterogeneity in main channels by delivery of coarse sediment that either causes slope decreases and sediment fining upstream, or slope increases and sediment coarsening downstream (Rice \& Church, 1998; Benda et al., 2004; Hanks \& Webb, 2006). Our study revealed tributaries in the summer were characterised by lower discharges and finer substrates than upstream or downstream mainstem sites in both rivers, but there were no differences in mean discharge or substrate composition between upstream and downstream sites, implying little evidence of tributary effects on mainstem physical habitat. However, not all tributaries cause geomorphic or hydraulic adjustments in recipient channels (Benda et al., 2004; Rice et al., 2006; Rice, 2017). The studied tributaries possessed low discharges (i.e. $0.11-1.09 \mathrm{~m}^{3} \mathrm{~s}^{-1}$ ), typical of summer months and thus, did not add a substantial volume of water or sediment to the main channel unlike previous studies (e.g. Rice \& Greenwood, 2001; Rice et al., 
Table 2 Longitudinal patterns in abundance of macroinvertebrates classified by order and FFGs in the regulated MFAR and the unregulated NFAR

Positive slopes indicate an increase with distance downstream, while a negative slope indicates a decrease downstream. Probabilities are significant at $* * P<0.01$ and $* P<0.05$

\begin{tabular}{|c|c|c|c|c|c|c|}
\hline \multirow[t]{2}{*}{ Drainage basin } & \multicolumn{3}{|l|}{ MFAR } & \multicolumn{3}{|l|}{ NFAR } \\
\hline & Significance & $R^{2}$ & Slope & Significance & $R^{2}$ & Slope \\
\hline \multicolumn{7}{|l|}{ Order } \\
\hline Coleoptera & 0.249 & 0.312 & + & 0.269 & 0.292 & + \\
\hline Diptera & 0.312 & 0.251 & - & 0.466 & 0.139 & - \\
\hline Ephemeroptera & $0.008^{* *}$ & 0.86 & + & 0.704 & 0.04 & + \\
\hline Plecoptera & $0.044 *$ & 0.678 & + & 0.089 & 0.555 & - \\
\hline Trichoptera & 0.278 & 0.282 & + & 0.172 & 0.408 & + \\
\hline Oligochaeta & 0.176 & 0.403 & - & 0.869 & 0.008 & - \\
\hline \multicolumn{7}{|l|}{ FFG } \\
\hline Filter-feeders & $0.046^{*}$ & 0.671 & + & 0.862 & 0.164 & + \\
\hline Grazers & 0.672 & 0.05 & + & 0.118 & 0.497 & + \\
\hline Collector-gatherers & $0.032 *$ & 0.645 & + & 0.726 & 0.034 & + \\
\hline Shredders & 0.592 & 0.078 & - & 0.301 & 0.067 & + \\
\hline Scrapers & 0.523 & 0.109 & + & 0.751 & 0.028 & + \\
\hline Predators & 0.608 & 0.072 & - & 0.487 & 0.238 & - \\
\hline
\end{tabular}

2001, 2006). The small size of the tributaries (indicated by the low discharges and the drainage basin size i.e. $7-87.5 \mathrm{~km}^{2}$ ) may partly account for the observed pattern in our data. Although our first hypothesis that tributaries will change physical habitat downstream of junctions in both rivers was not supported, the distinct physical habitat between tributaries and mainstem sites has ecological impacts for mobile taxa (Power \& Dietrich, 2002). Taxa able to colonise tributaries from mainstem locations through larval upstream dispersal (Elliott, 2003) and upstream flight dispersal as adults (Hershey et al., 1993) may benefit from differences in illumination, shading, substrate stability, lower discharges and turbidity. Tributaries may offer a velocity refuge and a more favourable habitat for breeding for sensitive species of macroinvertebrates from the successive flow pulses from regulated hydro-peaking operations in mainstem habitats.

Influence of tributaries on macroinvertebrate diversity and community composition downstream of junctions

Tributaries can increase diversity and alter macroinvertebrate community composition downstream of junctions through additional habitat variability, which has effects on river ecosystem functioning and health (Benda et al., 2004; Rice et al., 2006, 2008; Rice, 2017). However, we found no differences in mean faunal indices (e.g. TIA, taxonomic richness and Shannon-Weiner diversity) or community composition between upstream, downstream and tributary sites on the unregulated NFAR. Similar mainstem and tributary communities may be due to (1) comparable habitat conditions between tributary and mainstem locations leading to a lack of species sorting (i.e. habitat preference), (2) mass effects (source-sink dynamics) via invertebrate drift from tributary to downstream locations and (3) potentially upstream adult dispersal and colonisation of tributaries from mainstem locations (Wilson \& McTammany, 2014). However, our results did indicate mean faunal indices (e.g. TIA and Shannon-Weiner diversity) were higher and macroinvertebrate community composition was significantly different on tributaries than mainstem sites on the regulated MFAR. A strong longitudinal trend in taxonomic richness was present on the MFAR and overrode a tributary effect. Differing mainstem and tributary communities (e.g. TIA and ShannonWeiner diversity) on the MFAR may be due to different flow and sediment regimes caused by upstream hydro-peaking operations. The regular flow pulses from hydro-peaking operations often cause declines in macroinvertebrate abundance, taxonomic richness and diversity nearest a dam's discharge (Céreghino \& Lavandier, 1998; Patterson \& Smokorowski, 2011). Hydro-peaking operations may also cause transport of loose bed material and fine sediment 
from areas near a dam, creating more homogenous substrates and reducing habitat availability for macroinvertebrates, which further contributes to low abundance and diversity (Nilsson et al., 1997; Beisel et al., 2000). Therefore, this study does not support our second hypothesis that unregulated tributaries will modify invertebrate diversity and community composition downstream of tributary junctions in these regulated and unregulated rivers. Future studies would benefit from additional sampling around each tributary junction at multiple channel-width locations (e.g. 0.5, 1 and 2 channel widths from the junction) to increase the statistical power of the data.

Previous studies have identified varying effects of tributary junctions in differing flow conditions. Lower densities of macroinvertebrates were found in tributaries compared to mainstems during low-flows in the Acheron River, Australia, but densities were more similar in tributaries and mainstems during high flows (Mac Nally et al., 2011). Taxonomic richness was similar in tributaries and mainstems during low-flows, but increased in mainstems more than tributaries during high flows (Mac Nally et al., 2011). These findings revealed that flow magnitude at tributary junctions, which is influenced by the slope of the tributary to the mainstem, the angle of intersection, drainage basin size and precipitation levels (Benda \& Dunne, 1997; Benda \& Andras, 2004; Benda et al., 2004), are key factors in shaping macroinvertebrate community composition downstream of tributaries. We also found tributaries had similar faunal patterns and community composition with upstream and downstream sites during low-flows in the unregulated NFAR. In summer low flow periods, tributaries (i.e. low order headwaters) may not support high invertebrate abundances and diversity due to river contraction (Clarke et al., 2008, 2010), which decreases the amount of available habitat for most aquatic biota compared to conditions found at higher flows (Lake, 2003). Patterson \& Smokorowski (2011) found significantly higher abundances of drifting macroinvertebrates from tributaries to the mainstem Magpie River (Canada) in a spring season (i.e. high flows), but no difference in taxonomic richness. These findings indicate important seasonal influences (i.e. different flow conditions) of tributary effects on invertebrate communities and imply the influence of tributaries on downstream physical habitat and invertebrate communities varies temporally. Further research would benefit from identifying the seasonal patterns of tributary inputs on benthic invertebrate communities in regulated rivers.

Longitudinal patterns in functional feeding groups and taxonomic orders

On the MFAR, filter-feeders and collector-gatherers significantly increased with distance downstream (Table 2). High shear stress associated with flow pulses near dams can directly remove insects or damage their silk nets (Novotny, 1985; Troelsup \& Hergenrader, 1990; Boon, 1993). Hydropsychidae feeding nets can be broken at high velocities and appear to need a stable flow to function (Hauer et al., 1989). Collector-gatherers (including Caenis sp., Baetis sp. and Ephmerella sp.) also increased longitudinally in the MFAR. Patterson \& Smokorowski (2011) similarly found collector-gatherers increased with distance downstream on the regulated Magpie River. Possible mechanisms include the contribution of invertebrates and resources from tributaries and a more physically diverse habitat downstream. The data partly support our third hypothesis that filter-feeders and collector-gatherers would increase with distance from the impoundment. However, despite finding high abundances of predators near the dam, no longitudinal change was present as we predicted.

Ephemeroptera (including Ameletus sp., Acentrella sp., Baetis sp., Rhithrogena sp. and Paraleptophlebia sp. [Leptophlebiidae) and Plecoptera (dominated by Calineuria. californica, Suwallia sp. and Sweltsa sp. [Chloroperlidae]) significantly increased longitudinally on the MFAR (Table 2). Although Ephemeroptera vary in feeding strategies, morphologies and exhibit differing hydraulic preferences, specific taxa such as Baetis sp., Acentrella sp. and Ameletus sp. prefer stable substrates not embedded with fine sediment (Wooton et al., 1996), and faster-flowing habitats typical of sites with increasing distance from impoundments (n.b. mean discharge increased longitudinally on the regulated MFAR; $R^{2}=0.93$, $P<0.01)$. Downstream sites were also characterised by increased Plecoptera (largely Calineuria. californica). Plecoptera distributions are typically low or absent near dams due to modifications in temperature, substrate and food resources (Ward \& Stanford, 1995). The unregulated NFAR did not show any significant longitudinal trends in macroinvertebrates grouped by 
order or FFG. Longitudinal differences were not expected in the NFAR because of our relatively smaller sampling resolution $(9.3 \mathrm{~km})$ compared to the MFAR $(30.4 \mathrm{~km})$. In hindsight, it would have been preferable to sample comparable distances on both rivers. However, we believe our unregulated river would have demonstrated longitudinal trends in order and FFG if tributary inputs had had a distinct effect on macroinvertebrate communities downstream of junctions. The changes in FFGs and taxonomic order with distance downstream on the MFAR suggest biologic tributary inputs can be important for attenuating the ecological effects of river regulation. However, we are cognizant that community composition alters with natural longitudinal gradients, although stream order did not vary within our study area in the MFAR. Therefore, management activities should aim to protect the range of physical habitats and benthic assemblage structures unregulated tributaries provide to aid improvement of regulated river ecosystems.

\section{Conclusion}

The study revealed unregulated tributaries possessed higher mean TIA and diversity and a different invertebrate community composition compared to upstream and downstream mainstem sites on the regulated MFAR during summer low-flows. In contrast, tributaries had similar faunal patterns and community composition to upstream and downstream mainstem sites on the unregulated NFAR. The studied tributaries did not contribute a large volume of water or sediment to recipient channels contrary to previous work (e.g. Rice \& Greenwood, 2001; Rice et al., 2001, 2006), which explains the lack of distinct hydrological and sedimentological transitions between tributaries and downstream sites. While our data did not statistically support the hypothesis that river sites immediately downstream of tributary junctions exhibit greater faunal patterns than upstream, our data did demonstrate changes in FFG composition as distance downstream increased from the flow impairment point on the regulated river. Filter-feeders and collector-gatherers increased with distance from the Oxbow Powerhouse and Ralston Afterbay Dam, implying biologic inputs from tributaries may help to attenuate the negative ecological effects of river regulation. Our initial findings indicate unregulated tributaries should be safeguarded through conservation management and be promoted as valuable links in the landscape for enhancing biodiversity conservation. Studying the effects of unregulated tributaries across different seasons with attendant flow changes may aid further understanding of benthic invertebrate patterns in environments experiencing varying flow disturbances and contribute to increased understanding on the magnitude of ecological impacts due to flow regulation.

Acknowledgements This study was funded by a University of Worcester and a California State Energy Commission research grant. We would like to thank California State Parks for providing access to fieldwork sites and the use of kayaks for river crossings. A big thank-you to Nick Corline, Kyle Phillips, Catherine Fong, Rachel Klopfenstein, Zaira Lopez and Rob Lusardi for assistance in the field and macroinvertebrate processing and identification. Thanks to four anonymous reviewers whose comments and recommendations greatly improved this manuscript.

Open Access This article is distributed under the terms of the Creative Commons Attribution 4.0 International License (http:// creativecommons.org/licenses/by/4.0/), which permits unrestricted use, distribution, and reproduction in any medium, provided you give appropriate credit to the original author(s) and the source, provide a link to the Creative Commons license, and indicate if changes were made.

\section{References}

Anderson, M. J., R. N. Gorley \& K. R. Clarke, 2008. PERMANOVA+ for PRIMER: guide to software and statistical methods. PRIMER-E, Plymouth.

Anderson, R. G., Y. Jin \& M. L. Goulden, 2012. Assessing regional evapotranspiration and water balance across a Mediterranean montane climate gradient. Agricultural and Forest Meteorology 166-167: 10-22.

Beisel, J., P. Usseglio-Polatera \& J. Moreteau, 2000. The spatial heterogeneity of a river bottom: a key factor determining macroinvertebrate communities. Hydrobiologia 422(423): $163-171$.

Benda, L. \& K. Andras, 2004. Confluence effects in rivers: interactions of basin scale, network geometry, and disturbance regimes. Water Resources Research 40: W05402.

Benda, L. \& T. Dunne, 1997. Stochastic forcing of sediment routing and storage in channel networks. Water Resources Research 33: 2865-2880.

Benda, L., D. Miller, T. Dunne, L. Poff, G. Reeves, G. Pess \& M. Pollock, 2004. The network disturbance theory: how channel networks structure river habitats. Bioscience 54: 413-427.

Boon, P. J., 1993. Distribution, abundance and development of Trichoptera larvae in the river North Tyne following the 
commencement of hydroelectric power generation. Regulated Rivers: Research and Management 8: 211-224.

Bruno, M. C., B. Maiolini, M. Carolli \& L. Silveri, 2010. Short time-scale impacts of hydropeaking on benthic invertebrates in an Alpine stream (Trentino, Italy). Limnologica 40: 281-290.

Bruns, D. A., G. W. Minshall, C. E. Cushing, K. W. Cummins, J. T. Brock \& R. L. Vannote, 1984. Tributaries as modifiers of the river continuum concept-analysis by polar ordination and regression-models. Archive für Hydrobiologie 99: 208-220.

Bunn, S. E. \& A. H. Arthington, 2002. Basic principles and ecological consequences of altered flow regimes for aquatic biodiversity. Environmental Management 30: 492-507.

California Protected Areas, 2018. California protected areas database. http://www.calands.org/ (Accessed 21 May 2018).

Camargo, J. \& N. Voelz, 1998. Biotic and abiotic changes along the recovery gradient of two impounded rivers with different impoundment use. Environmental Monitoring and Assessment 50: 143-158.

Céreghino, R. \& P. Lavandier, 1998. Influence of hypolimnetic hydropeaking on the distribution and population dynamics of Ephemeroptera in a mountain stream. Freshwater Biology 40: 385-399.

Céréghino, R., P. Cugny \& P. Lavandier, 2002. Influence of intermittent hydropeaking on the longitudinal zonation patterns of benthic invertebrates in a mountain stream. International Review of Hydrobiology 87: 47-60.

Clarke, K. R. \& R. N. Gorley, 2006. PRIMER v6: user manual/tutorial. PRIMER E-Ltd, Plymouth.

Clarke, A., R. Mac Nally, N. Bond \& P. S. Lake, 2008. Macroinvertebrate diversity in headwater streams: a review. Freshwater Biology 53: 1707-1721.

Clarke, A., R. Mac Nally, N. Bond \& P. S. Lake, 2010. Flow permanence affects aquatic macroinvertebrate diversity and community structure in three headwater streams in a forested catchment. Canadian Journal of Fisheries and Aquatic Sciences 67: 1649-1657.

Cushman, R. M., 1985. Review of the ecological effects of rapidly varying flows downstream from hydroelectric facilities. North American Journal of Fisheries Management 5: 330-339.

Czeglédi, I., P. Sály, P. Takács, A. Dolezsai, S. A. Nagy \& T. Erös, 2016. The scales of variability on stream fish assemblages at tributary confluences. Aquatic Sciences 78: 641-654.

Elliott, J. M., 2003. A comparative study of the dispersal of 10 species of stream invertebrates. Freshwater Biology 48: 1652-1668.

Ellis, L. E. \& N. E. Jones, 2013. Longitudinal trends in regulated rivers: a review and synthesis within the context of the serial discontinuity concept. Environmental Reviews 21: 136-148.

Hanks, T. C. \& R. H. Webb, 2006. Effects of tributary debris on the longitudinal profile of the Colorado River in Grand Canyon. Journal of Geophysical Research: Earth Surface 11: F02020.

Hauer, F. R., J. A. Stanford \& J. V. Ward, 1989. Serial discontinuities in a rocky mountain river. Distribution and abundance of Trichoptera. Regulated Rivers: Research and Management 3: 177-182.

Hershey, A. E., J. Pastor, B. J. Peterson \& G. W. Kling, 1993. Stable isotopes resolve the drift paradox for Baetis mayflies in an arctic river. Ecology 74: 2315-2325.

Hladyz, S., D. L. Nielson, P. J. Suter \& E. S. Krull, 2012. Temporal variations in organic carbon utilization by consumers in a lowland river. River Research and Applications 28: 513-528.

Johnson, W. C., 2002. Riparian vegetation diversity along regulated rivers: contributing of novel and relict habitats. Regulated Rivers: Research \& Management 16: 421-432.

Jones, N. E., 2011. Spatial patterns in invertebrates in regulated and natural rivers. River Research and Applications 29: 343-351.

Jones, N. E., 2013. Patterns of benthic invertebrate richness and diversity in the regulated Magpie River and neighbouring natural rivers. River Research and Applications 29(9): 1090-1099.

Junk, W. J., P. B. Bayley, R. E. Sparks, 1989. The flood pulse concept in river-floodplain systems. In Dodge, D. P. (ed), Proceedings of the International Large River Symposium. Canadian Journal of Fisheries and Aquatic Sciences 106: 110-127.

Katano, I., J. N. Negishi, T. Minagawa, H. Doi, Y. Kawaguchi \& Y. Kayaba, 2009. Longitudinal macroinvertebrate organization over contrasting discontinuities: effects of a dam and a tributary. Journal of the North American Benthological Society 28: 331-351.

Kjærstad, G., J. V. Arnekleiv, J. D. M. Speed \& A. K. Herland, 2018. Effects on hydropeaking on benthic invertebrate community composition in two central Norwegian rivers. River Research and Applications 34: 218-231.

Knispel, S. \& E. Castella, 2003. Disruption of a longitudinal pattern in environmental factors and benthic fauna by a glacial tributary. Freshwater Biology 48: 604-618.

Lake, P. S., 2003. Ecological effects of perturbation by drought in flowing waters. Freshwater Biology 48: 1161-1172.

Leopold, L. B., M. G. Wolman \& J. P. Miller, 1964. Fluvial Processes in Geomorphology. WH. Freeman and Company, San Francisco.

Mac Nally, R., E. Wallis \& P. S. Lake, 2011. Geometry of biodiversity patterning: assemblages of benthic macroinvertebrates at tributary confluences. Aquatic Ecology 45: 43-54.

McLaughlin, F., M. Lapointe, G. Bourque \& D. Boisclair, 2014. Using regional flow classes as references to analyse flow regime anomalies across a set of regulated Canadian rivers. Journal of Hydrology 519: 307-328.

Merritt, R. W., K. W. Cummins \& M. B. Berg, 2008. An Introduction to the Aquatic Insects of North America, 4th ed. Kendall Hunt Publishing Company, Dubuque.

Moss, B., 2010. Ecology of Freshwaters. A View for the Twenty-First Century, 4th ed. Wiley, Chichester.

Munn, M. D. \& M. A. Brusven, 2004. The influence of Dworshak Dam on epilithic community metabolism in the Clearwater River, U.S.A. Hydrobiologia 513: 121-127.

Nilsson, C., R. Jansson \& U. Zinko, 1997. Long-term response of river-margin vegetation to water-level regulation. Science 276: 798-800. 
Novotny, J. F., 1985. Effects of a Kentucky flood-control reservoir on macroinvertebrates in the tailwater. Hydrobiologia 126: 143-153.

Patterson, R. J. \& K. E. Smokorowski, 2011. Assessing the benefit of flow constraints on the drifting invertebrate community of a regulated river. River Research and Applications 27: 99-112.

Petts, G. E., 1988. Accumulation of fine sediment within substrate gravels along two regulated rivers, UK. Regulated Rivers: Research and Management 2(2): 141-153.

Placer County Water Agency, 2007. Existing Resources. URL. Available at: http://relicensing.pcwa.net/ pdf/pad/ExecSum/ExecSumExistingResources.pdf (Accessed 31 May 2016).

Power, M. E. \& W. E. Dietrich, 2002. Food webs in river networks. Ecological Research 17: 451-471.

Pringle, C., 2003. What is hydrologic connectivity and why is it ecologically important? Hydrological Processes 17: 2685-2689.

Reidy Liermann, C. A., C. Nilsson, J. Robertson \& R. Y. Ng, 2012. Implications of dam obstruction for global freshwater fish diversity. Bioscience 62: 539-548.

Rice, S. P., 2017. Tributary connectivity, confluence aggradation and network biodiversity. Geomorphology 277: 6-16.

Rice, S. P. \& M. Church, 1998. Grain size along two gravel-bed rivers: statistical variation, spatial pattern and sedimentary links. Earth Surface Processes and Landforms 23(4): 345-363.

Rice, S. P. \& M. T. Greenwood, 2001. Macroinvertebrate community changes at coarse sediment recruitment points along two gravel bed rivers. Water Resources Research 37(11): 2793-2803.

Rice, S. P., M. T. Greenwood \& C. B. Joyce, 2001. Tributaries, sediment sources, and the longitudinal organisation of macroinvertebrate fauna along river systems. Canadian Journal of Fisheries and Aquatic Sciences 58: 824-840.

Rice, S. P., R. I. Ferguson \& T. B. Hoey, 2006. Tributary control of physical heterogeneity and biological diversity and river confluences. Canadian Journal of Fisheries and Aquatic Sciences 63: 2553-2556.

Rice, S. P., R. I. Ferguson, P. Greene \& T. B. Hoey, 2008. The ecological importance of tributaries and confluences. In Rice, S. P., A. G. Roy \& B. L. Rhoad (eds), River Confluences, Tributaries, and the Fluvial Network. Wiley, Chichester: 209-242.

Smith, S. C. F., S. J. Meiners, R. P. Hastings, T. Thomas \& R. E. Colombo, 2017. Low-head dam impacts on habitat and the functional composition of fish communities. River Research and Applications 33: 680-689.

Stevens, L. E., J. P. Shannon \& D. W. Blinn, 1997. Colorado river benthic ecology in Grand Canyon, Arizona, USA: dam, tributary and geomorphological influences. Regulated Rivers: Research and Management 13: 129-149.
Stubbington, R. S., A. J. Boulton, S. Little \& P. J. Wood, 2015. Changes in invertebrate assemblage composition in benthic and hyporheic zones during a severe supraseaonal drought. Freshwater Science 34: 344-354.

Thornburgh, D. J. \& K. B. Gido, 2010. Influence of spatial positioning within stream networks on fish assemblage structure in the Kansas River basin, USA. Canadian Journal of Fisheries and Aquatic Sciences 67: 143-156.

Tonkin, J. D., F. Altermatt, D. S. Finn, J. Heino, J. D. Olden, S. U. Pauls \& D. A. Lytle, 2018. The role of dispersal in river network metacommunities: patterns, processes and pathways. Freshwater Biology 63: 141-163.

Troelsup, N. H. \& G. L. Hergenrader, 1990. Effect of hydropower peaking flow fluctuations on community structure and feeding guilds and invertebrates colonizing artificial substrates in a large impounded river. Hydrobiologia 199: 2017-2228.

United States Geological Survey, 2017. National Water Information System. https://waterdata.usgs.gov/nwis/ uv?07057500 (Accessed 20 July 2017).

Vehanen, T., 2000. Effect of fluctuating flow and temperature on cover type selection and behaviour by juvenile brown trout in artificial flumes. Journal of Fish Biology 56: 923-937.

Vinson, M. R., 2001. Long-term dynamics of an invertebrate assemblage downstream from a large dam. Ecological Applications 11: 711-730.

Vörösmarty, C. J., P. B. McIntyre, M. O. Gessner, D. Dudgeon, A. Prusevich, P. Green, S. Glidden, S. E. Bunn, C. A. Sullivan, C. Reidy Liermann \& P. M. Davies, 2010. Global threats to human water security and river biodiversity. Nature 465: 555-561.

Wallis, E., R. Mac Nally \& S. Lake, 2009. Do tributaries affect loads and fluxes of particulate organic matter, inorganic sediment and wood? Patterns in an upland river basin in south-eastern Australia. Hydrobiologia 636: 307-317.

Ward, J. V., 1975. Downstream fate of zooplankton from a hypolimnial release mountain reservoir. Verhandlungen des Internationalen Verein Limnologie 19: 1798-1804.

Ward, J. V. \& J. A. Stanford, 1995. The serial discontinuity concept: extending the model to floodplain-rivers. Regulated Rivers Research and Management 10: 159-168.

Wiggins, G., 2000. Larvae of the North American Caddisfly Genera (Trichoptera), 2nd ed. University of Toronto Press, Toronto.

Wilson, M. J. \& M. E. McTammany, 2014. Tributary and mainstem benthic macroinvertebrate communities linked by direct dispersal and indirect habitat alteration. Hydrobiologia 783: 75-85.

Wooton, J. T., M. Parker \& M. E. Power, 1996. Effects of disturbance on river food webs. Science 73(5281): 1558-1561. 